\title{
Investigation of Protective Effect of Polymeric Film Coatings on Carbon Steel in Aggressive Solutions
}

\author{
Florina Branzoi ${ }^{1, *}$ and Viorel Branzoi ${ }^{2}$ \\ ${ }^{1}$ Institute of Physical Chemistry "Ilie Murgulescu" 202 Splaiul Independenţei, 060021 Bucharest, \\ Romania \\ ${ }^{2}$ Department of Applied Physical Chemistry and Electrochemistry, University Politehnica of \\ Bucharest, 132 Calea Grivitei, 010737 Bucharest, Romania \\ E-mail: fbrinzoi@ chimfiz.icf.ro
}

doi: $10.20964 / 2016.08 .16$

Received: 8 April 2016 / Accepted: 26 May 2016 / Published: 7 July 2016

In this paper, galvanostatic electropolymerization technique has been used for to obtain of new composite (PPY-SDS/PNNDMA and PNNDMA/ PPY-SDS) coatings onto carbon steel of type OL 37 for corrosion protection. Monolayer poly (N, N' dimethylaniline) (PNNDMA), polypyrrole (PPY), and bilayer PNNDMA/PPY-SDS and PPY-SDS/PNNDMA coatings were electrodeposition on carbon steel by galvanostatic methods from synthesis solutions $0.1 \mathrm{M}$ N,N' dimethylaniline, $0.1 \mathrm{M}$ pyrrole, $0.01 \mathrm{M}$ sodium dodecyl sulfate (SDS) with $0.3 \mathrm{M} \mathrm{H}_{2} \mathrm{C}_{2} \mathrm{O}_{4}$. It was used dodecylsulfate ions as dopant to polypyrrole, SDS has been likewise introduced into the synthesis solution of polypyrrole. The properties of monolayer and bilayer composite polymer have been realized out by electrochemical voltammetry, FT-IR analysis and SEM measurements. The anticorrosive properties of the OL37 coated has been studied by electrochemical polarization and EIS measurements in $0.5 \mathrm{M} \mathrm{H}_{2} \mathrm{SO}_{4}$ medium. The analysis of the corrosion protection samples demonstrated that PNNDMA/PPY-SDS coatings assure a great anticorrosive performance of carbon steel in corrosive environments. Bilayer composite polymer showed greater corrosion protection effectiveness compared to monolayer composite polymer.

Keywords: nanocomposite films, galvanostatic electrodeposition, corrosion protection, SEM, EIS, FTIR

\section{FULLTEXT}

(C) 2016 The Authors. Published by ESG (www.electrochemsci.org). This article is an open access article distributed under the terms and conditions of the Creative Commons Attribution license (http://creativecommons.org/licenses/by/4.0/). 